\title{
Características de carcaça de codornas de corte EV1 alimentadas com diferentes níveis de metionina+cistina total
}

\author{
[Carcass traits of EV1 quail strain fed different methionine+cystine level diets] \\ F. Ferreira ${ }^{1}$, G.S.S. Corrêa ${ }^{2}$, A.B. Corrêa ${ }^{3}$, M.A. Silva ${ }^{4}$,V.P.S. Felipe ${ }^{1}$, R.R. Wenceslau ${ }^{1}$, L.S. Freitas ${ }^{5}$, \\ G.G. Santos ${ }^{6}$, R.M. Godinho ${ }^{1}$, W.L.S. Climaco ${ }^{1}$, L.S. Dalsecco ${ }^{1}$, J.G. Caramori Júnior ${ }^{3}$ \\ ${ }^{1}$ Alunos de pós-graduação - EV-UFMG - Belo Horizonte, MG \\ ${ }^{2}$ Universidade Federal de Mato Grosso - FAMEV - Membro do INCT/CA/UFMT \\ 3Universidade Federal de Mato Grosso - FAMEV \\ ${ }^{4}$ Escola de Veterinária - UFMG - Belo Horizonte, MG - Bolsista CNPq \\ ${ }^{5}$ Geneticista DB-Genética Suína \\ ${ }^{6}$ Embrapa Gado de Leite - Juiz de Fora, MG
}

\begin{abstract}
RESUMO
O peso e o rendimento das carcaças de codornas de corte da linhagem EV1 foram avaliados no $35^{\circ}$ dia de idade em delineamento experimental inteiramente ao acaso, com os tratamentos consistidos de um fatorial 2 x 6, ou seja, dois sexos e seis níveis de metionina+cistina totais $(0,73 ; 0,79 ; 0,85 ; 0,91 ; 0,97$ e $1,03 \%)$, quatro repetições e 12 aves por unidade experimental. Foram avaliados peso corporal, peso e rendimento de carcaça, peito, coxa, asas, vísceras comestíveis e gordura abdominal. Não houve efeito da interação sexo x nível de metionina das dietas para nenhuma das variáveis analisadas. Houve efeito quadrático dos níveis de metionina+cistina sobre peso corporal, carcaça, peito, coxa, asa e coração, com pontos de máximo em $0,93 \%$ para peso corporal, carcaça, peito e coxa; $0,90 \%$ para peso de asa e $0,92 \%$ para peso de coração. $\mathrm{O}$ peso de fígado aumentou de forma linear à medida que foram aumentados os níveis de metionina+cistina das dietas. Os níveis de metionina+cistina da dieta influenciaram de forma quadrática nos rendimentos de peito e asas, com pontos de máximo estimados para codornas alimentadas com dietas contendo $0,96 \%$ e $0,98 \%$ de metionina+cistina, respectivamente. O maior rendimento de moela foi obtido nas codornas alimentadas com $0,73 \%$ de metionina+cistina. O peso corporal de carcaça, peito, coxa, asa, fígado, moela e o rendimento de fígado nas fêmeas foram maiores que nos machos. A exigência de metionina+cistina para pesos de carcaça e peito é $0,93 \%$, e para rendimento de peito $0,96 \%$.
\end{abstract}

Palavras-chave: codorna, aminoácido, exigência, rendimento de carcaça

\begin{abstract}
Carcass weight and yield of European quail strain EV1 were evaluated at 35 days of age in a completely randomized experimental design, with the treatments consisting of a $2 \times 6$ factorial combination, two sexes and six different methionine+cystine levels of diets (.73; .79; .85; .91; .97 and 1.03\%), with four replicates and 12 quails per experimental unit. Body weight, weights and yields of carcass, breast, thigh, wing and, edible giblets and abdominal fat were recorded. Significant and quadratic effect of methionine+cystine level on body weight, weights of carcass, breast, thigh and heart were observed with estimated maximum of body weight and weights of carcass, breast and thigh for quails fed .93\% methionine+cystine diets, . $90 \%$ for wing weight and .92\% for heart weight. Increasing and linear response of liver weight to methionine+cystine level of diet was estimated while breast and wing yields showed quadratic responses with estimated maximum for quails fed .96\% and $.98 \%$ methionine+cystine level diets. Higher gizzard yield was observed for quails fed .73\% diets. Higher body weight, and weights of carcass, thigh, wing, liver, gizzard and liver yields were estimated for females. Methionine+cystine requirement for quail carcass and breast weights is .93\% and for breast yield .96\%.
\end{abstract}

Keywords: quail, amino acid, requirement, carcass yield

Recebido em 13 de outubro de 2012

Aceito em 25 de junho de 2014

E-mail: fabianaferreira@zootecnista.com.br 


\section{INTRODUÇÃO}

A carne de codornas comercializada no passado era proveniente exclusivamente de fêmeas destinadas à produção de ovos no final do ciclo de produção, resultando, assim, em carcaças muito pequenas (70-110g) e carne relativamente dura, por se tratar de aves com aproximadamente um ano de idade (Garcia, 2002). Atualmente, esse cenário mudou e existe produção de codornas especializadas para a produção de carne, as quais são abatidas aos 42 dias de idade, com peso variando entre $200-300 \mathrm{~g}$.

No Brasil, apenas uma empresa alimentícia de grande porte produz e comercializa codornas para corte, sendo essas aves comercializadas em embalagens contendo aproximadamente cinco carcaças com peso aproximado de 200 gramas cada carcaça, enquanto nos Estados Unidos, além desse tipo de carcaça, são comercializadas codornas desossadas da espécie Bobwhite, com até 300 gramas pós-processamento (Murakami e Ariki, 1998).

Para se obter máximo rendimento de carcaça de codornas destinadas à produção de carne, há necessidade do conhecimento das exigências nutricionais dessas aves e formulação de dietas que atendam suas exigências, principalmente em aminoácidos. No entanto, a formulação de dietas de codornas destinadas à produção de carne tem sido feita com base nas informações do NRC (Nutrient..., 1994) que se referem às exigências de codornas japonesas, destinadas à produção de ovos e que apresentam peso e rendimento de carcaças completamente diferentes das codornas de corte.

As fontes proteicas, por serem os componentes de maiores participação e importância nas formulações de dietas, devem estar em quantidades adequadas para suprirem as necessidades das codornas, sem onerar o seu custo de produção (Corrêa et al., 2007). Além disso, as dietas para codornas são usualmente elaboradas com base no conteúdo de proteína bruta, o que pode acarretar consumo excessivo de aminoácidos, com reflexo negativo sobre a conversão alimentar, o ganho de peso e a qualidade da carcaça.

A utilização de aminoácidos industriais permitiu a formulação de dietas com menores teores de proteína bruta do que os recomendados em tabelas de exigências nutricionais. Com isso, pode-se maximizar a utilização dos aminoácidos para síntese proteica, minimizar seu uso como fonte de energia e favorecer a obtenção do máximo desempenho das codornas (Corrêa et al., 2006).

A metionina e a cistina são aminoácidos considerados fisiologicamente essenciais para mantença, crescimento e para o desenvolvimento das penas (Pinto et al., 2003), porém somente a metionina é dieteticamente essencial, uma vez que ela, no organismo animal, pode ser convertida à cistina. A metionina é o primeiro aminoácido limitante para aves alimentadas com dietas à base de milho e farelo de soja, ingredientes normalmente utilizados na formulação das dietas. As exigências de metionina+cistina e demais aminoácidos são normalmente estabelecidas para taxa de crescimento e eficiência alimentar. Entretanto, outras características, como deposição de gordura abdominal, rendimento e composição de carcaça e vísceras comestíveis, são importantes e podem influenciar o rendimento de carne das codornas de corte.

Além disso, estudos sobre a influência de aminoácidos sobre a composição de carcaças, ainda são escassos, principalmente durante a fase final de criação (Schutte e Pack, 1995). Apesar de sua importância, é extremamente baixo o número de pesquisas que descrevem e quantificam as relações entre o conteúdo de metionina na dieta e as características de carcaça de codornas destinadas à produção de carne, como o realizado por Corrêa et al. (2010). Esses autores, ao testarem dietas para codornas de corte contendo diferentes níveis de metionina+cistina, não encontraram no $42^{0}$ dia de idade efeito do nível nutricional da dieta sobre os pesos e os rendimentos de carcaças, de cortes principais, e de vísceras comestíveis de codornas destinadas à produção de carne. A escassez de informação científica nessa área norteou a realização deste trabalho, que teve por objetivo avaliar o efeito de dietas contendo diferentes níveis de metionina+cistina, fornecidas do nascimento ao abate, sobre o peso e o rendimento de carcaças e vísceras comestíveis de codornas destinadas à produção de carne. 


\section{Características de carcaça...}

\section{MATERIAL E MÉTODOS}

Utilizaram-se 288 codornas de corte da linhagem EV1 de ambos os sexos, com peso médio inicial de 9,16g, em delineamento experimental inteiramente ao acaso em esquema fatorial $2 \times 6$, ou seja, dois sexos e seis níveis de metionina+cistina $(0,73 ; 0,79 ; 0,85 ; 0,91 ; 0,97$ e 1,03\%), quatro repetições e 12 aves por unidade experimental. As codornas foram alojadas em baterias de arame galvanizado, com dimensões de $0,82 \mathrm{~m}$ de largura $\mathrm{x} 0,41 \mathrm{~m}$ de profundidade $\mathrm{x}$ $0,27 \mathrm{~m}$ de altura por unidade experimental, equipadas com bebedouro copo e comedouro tipo calha. Adotou-se um programa de luz de 24 horas, durante toda a fase experimental.

As dietas experimentais foram formuladas com base nas informações nutricionais de composições dos ingredientes apresentadas por Rostagno et al. (2005) e, para atender as exigências nutricionais das codornas, utilizou-se o NRC (Nutrient..., 1994), exceto para metionina+cistina (objeto de estudo). A dieta basal (Tab. 1), formulada à base de milho e farelo de soja, continha $23,89 \%$ de proteína bruta (PB) e 2900kcal de EM/kg de dieta, suplementada com cinco níveis de DL-metionina (99\%), em substituição ao amido de milho, o que corresponde aos níveis de 0,73 (dieta basal sem suplementação); 0,79; 0,85; 0,91; 0,97 e 1,03\% de metionina+cistina total, permanecendo as dietas isocalóricas e isoproteicas. As dietas e a água foram fornecidas à vontade.

Para avaliação das características de carcaça, no $35^{\circ}$ dia de idade, duas codornas de cada unidade experimental (um macho e uma fêmea), após jejum de sólidos de oito horas, foram amostradas, pesadas, abatidas, depenadas, evisceradas e avaliadas quanto aos pesos e rendimentos dos cortes (peito, coxas e asas), vísceras comestíveis (fígado, moela e coração) e gordura abdominal em relação ao peso da carcaça eviscerada (sem pés e sem cabeça), segundo metodologia descrita por Corrêa et al. (2005).

O rendimento de carcaça, expresso em porcentagem, foi obtido pela relação entre o peso da carcaça eviscerada e o peso ao abate. Os rendimentos dos cortes, vísceras comestíveis e gordura abdominal foram calculados com relação ao peso da carcaça eviscerada.
Tabela 1. Composição percentual e calculada da dieta basal

\begin{tabular}{|c|c|}
\hline Ingredientes & $\%$ \\
\hline Milho & 53,469 \\
\hline Farelo de soja & 41,954 \\
\hline Calcário & 1,072 \\
\hline Óleo de soja & 1,016 \\
\hline Fosfato bicálcico & 0,960 \\
\hline Amido & 0,500 \\
\hline $\begin{array}{l}\text { Suplemento mineral e } \\
\text { vitamínico }{ }^{1}\end{array}$ & 0,500 \\
\hline Sal comum & 0,265 \\
\hline L-treonina & 0,265 \\
\hline Total & 100,00 \\
\hline \multicolumn{2}{|l|}{ Composição calculada } \\
\hline Proteína bruta (\%) & 23,886 \\
\hline $\begin{array}{l}\text { Energia metabolizável } \\
\text { (kcal/kg) }\end{array}$ & 2.900 \\
\hline Cálcio (\%) & 0,800 \\
\hline Fósforo disponível (\%) & 0,300 \\
\hline Sódio (\%) & 0,150 \\
\hline \multicolumn{2}{|l|}{ Aminoácidos totais } \\
\hline Lisina (\%) & 1,300 \\
\hline Metionina+cistina (\%) & 0,731 \\
\hline Triptofano (\%) & 0,305 \\
\hline Metionina (\%) & 0,464 \\
\hline Arginina (\%) & 1,612 \\
\hline Isoleucina (\%) & 1,040 \\
\hline Valina (\%) & 1,107 \\
\hline \multicolumn{2}{|c|}{ 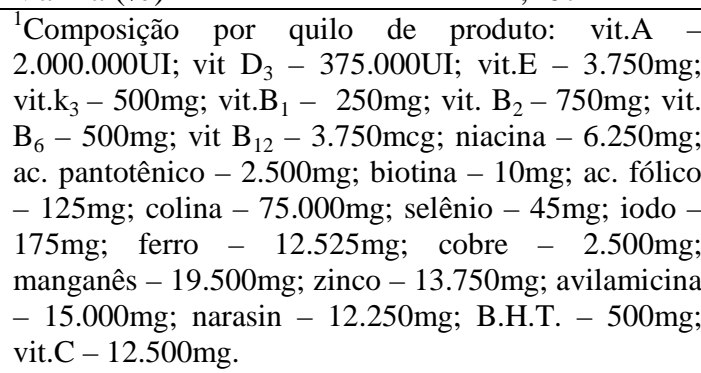 } \\
\hline
\end{tabular}

As análises dos dados foram realizadas considerando-se o modelo estatístico que incluía os efeitos dos níveis de metionina+cistina, sexo e a interação sexo x nível de metionina. $O$ efeito do nível de metionina+cistina, respeitando-se a significância da interação, foi estimado por intermédio de análise de regressão, desdobrandose os graus de liberdade desse fator em seus componentes lineares e quadráticos para escolha do modelo de regressão que melhor descrevesse as observações. O efeito do sexo foi avaliado por meio do teste de Fisher, ao nível de 5\% de probabilidade. $\mathrm{O}$ pacote computacional utilizado 
nas análises estatística foi o SAEG (Sistema..., 2009).

\section{RESULTADOS E DISCUSSÃO}

Não houve efeito significativo da interação sexo $\mathrm{x}$ nível de metionina sobre nenhuma das varáveis analisadas. Houve efeito quadrático $(\mathrm{P}<0,05)$ dos níveis de metionina+cistina sobre os pesos corporais, da carcaça, dos cortes principais e do peso do coração (Tab. 2), com máximos peso corporal (Fig. 1), carcaça (Fig. 2), peito (Fig. 3) e coxa (Fig. 4), estimados para codornas alimentadas com dietas contendo 0,93\% de metionina+cistina total, $0,90 \%$ para peso de asa (Fig. 5) e 0,92\% para peso de coração (Fig. 6).

Houve efeito linear significativo do nível de metionina+cistina com maiores pesos de fígado observados para codornas alimentadas com maior nível estudado (1,03\%). As fêmeas apresentaram maiores pesos corporal, de carcaça, peito, coxa, asa, fígado e moela do que os machos (Tab. 2), independentemente dos níveis nutricionais das dietas experimentais. Segundo Silva et al. (2006), fêmeas de codornas europeias apresentam peso corporal $10 \%$ maior do que os machos da sexta à oitava semana de vida, em decorrência de maiores pesos de seus órgãos reprodutivos.

Tabela 2. Peso corporal (g), peso de carcaça (g), peso de peito (g), peso de coxa (g), peso de fígado (g), peso de moela (g), peso de coração (g), peso de gordura abdominal (g), em relação aos níveis de metionina+cistina da dieta

\begin{tabular}{|c|c|c|c|c|c|c|c|c|}
\hline \multirow{2}{*}{ Variável } & \multirow{2}{*}{ Sexo } & \multicolumn{6}{|c|}{ Níveis de metionina+cistina total (\%) } & \multirow{2}{*}{ Média ${ }^{1}$} \\
\hline & & 0,73 & 0,79 & 0,85 & 0,91 & 0,97 & 1,03 & \\
\hline \multirow{2}{*}{ Peso corporal (g) } & $\mathrm{M}$ & 167,70 & 208,17 & 240,52 & 237,62 & 222,52 & 213,95 & $215,08 \mathrm{~B}$ \\
\hline & $\mathrm{F}$ & 183,62 & 244,22 & 272,30 & 264,67 & 266,30 & 280,57 & $251,95 \mathrm{~A}$ \\
\hline \multirow{2}{*}{$\begin{array}{l}\text { Peso de carcaça } \\
\text { (g) }\end{array}$} & M & 116,13 & 152,55 & 172,12 & 177,65 & 163,42 & 159,00 & $156,81 B$ \\
\hline & $\mathrm{F}$ & 129,80 & 175,90 & 186,27 & 190,37 & 185,90 & 190,40 & $176,44 \mathrm{~A}$ \\
\hline \multirow{2}{*}{$\begin{array}{l}\text { Peso de } \\
\text { peito (g) }\end{array}$} & $\mathrm{M}$ & 42,16 & 60,60 & 69,85 & 73,57 & 65,42 & 64,70 & $62,72 \mathrm{~B}$ \\
\hline & $\mathrm{F}$ & 48,20 & 69,17 & 75,22 & 75,30 & 75,22 & 79,05 & $70,36 \mathrm{~A}$ \\
\hline \multirow{2}{*}{$\begin{array}{l}\text { Peso de } \\
\text { coxa (g) }\end{array}$} & $\mathrm{M}$ & 30,36 & 37,67 & 41,45 & 44,42 & 40,20 & 38,75 & $38,81 \mathrm{~B}$ \\
\hline & $\mathrm{F}$ & 33,22 & 43,37 & 42,55 & 47,40 & 45,92 & 47,22 & $43,28 \mathrm{~A}$ \\
\hline \multirow{2}{*}{ Peso de asa (g) } & M & 10,76 & 11,92 & 13,75 & 13,52 & 12,70 & 11,12 & $12,23 \mathrm{~B}$ \\
\hline & $\mathrm{F}$ & 10,92 & 13,35 & 13,15 & 14,17 & 13,32 & 13,47 & $13,06 \mathrm{~A}$ \\
\hline \multirow{2}{*}{$\begin{array}{l}\text { Peso de } \\
\text { fígado (g) }\end{array}$} & $\mathrm{M}$ & 3,83 & 3,97 & 4,00 & 4,22 & 3,85 & 4,12 & $4,00 \mathrm{~B}$ \\
\hline & $\mathrm{F}$ & 4,77 & 6,47 & 7,25 & 7,15 & 9,60 & 8,10 & $7,22 \mathrm{~A}$ \\
\hline \multirow{2}{*}{$\begin{array}{l}\text { Peso de } \\
\text { moela (g) }\end{array}$} & M & 3,93 & 4,25 & 4,17 & 4,65 & 4,02 & 3,62 & $4,11 \mathrm{~B}$ \\
\hline & $\mathrm{F}$ & 4,87 & 4,92 & 4,87 & 4,92 & 4,85 & 4,67 & $4,85 \mathrm{~A}$ \\
\hline \multirow{2}{*}{$\begin{array}{l}\text { Peso de } \\
\text { coração (g) }\end{array}$} & $\mathrm{M}$ & 1,60 & 2,05 & 2,12 & 2,22 & 2,02 & 2,02 & $2,01 \mathrm{~A}$ \\
\hline & $\mathrm{F}$ & 1,60 & 2,07 & 2,42 & 2,17 & 2,15 & 2,27 & $2,11 \mathrm{~A}$ \\
\hline \multirow{3}{*}{$\begin{array}{l}\text { Peso de gord. } \\
\text { abdominal (g) }\end{array}$} & M & 0,80 & 0,82 & 1,25 & 1,75 & 0,95 & 2,20 & $1,29 \mathrm{~A}$ \\
\hline & $\mathrm{F}$ & 1,35 & 1,95 & 2,37 & 2,15 & 1,62 & 1,75 & $1,86 \mathrm{~B}$ \\
\hline & Equaç & s de regre & ão signifi & ivas para & veis de $n$ & onina $+c$ & \multicolumn{2}{|c|}{$\begin{array}{c}\text { Ponto de máximo } \\
\text { ponto de melhor } \\
\text { desempenho }\end{array}$} \\
\hline \multicolumn{2}{|l|}{ Peso corporal } & \multicolumn{6}{|c|}{$\hat{Y}_{i}=-1486,88+3752,91_{X_{i}}-2016,62 X_{i}^{2} \quad\left(\mathrm{R}^{2}=0,90\right)$} & 0,93 \\
\hline \multicolumn{2}{|l|}{ Peso de carcaça } & \multicolumn{6}{|c|}{$\hat{Y}_{i}=-1161,79+2909,02 X_{i}-1569,57 X_{i}^{2} \quad\left(\mathrm{R}^{2}=0,93\right)$} & 0,93 \\
\hline \multicolumn{2}{|l|}{ Peso de peito } & \multicolumn{4}{|c|}{$\hat{Y}_{i}=-536,12+1312,06 X_{i}-703,37 X_{i}^{2}$} & $0,92)$ & \multicolumn{2}{|c|}{0,93} \\
\hline \multicolumn{2}{|l|}{ Peso de coxa } & \multicolumn{4}{|c|}{$\hat{Y}_{i}=-228,51+586,85 X_{i}-314,61 X_{i}^{2}$} & $0,92)$ & \multicolumn{2}{|c|}{0,93} \\
\hline \multicolumn{2}{|l|}{ Peso de asa } & \multicolumn{4}{|c|}{$\hat{Y}_{i}=-66,20+176,56 X_{i}-97,53 X_{i}^{2}$} & $0,97)$ & \multicolumn{2}{|r|}{0,90} \\
\hline \multicolumn{2}{|l|}{ Peso de fígado $^{2}$} & \multicolumn{4}{|c|}{$\hat{Y}_{i}=0,016+6,37 X_{i}$} & $0,78)$ & & 1,03 \\
\hline Peso de coração & & $\hat{Y}_{i}=-12$ & $+32,99_{1}$ & $17,92 X_{i}$ & & $0,81)$ & & 0,92 \\
\hline
\end{tabular}

${ }^{1}$ Médias seguidas por letras distintas na coluna, entre os sexos, dentro de cada variável diferem entre si pelo teste de Fisher $(\mathrm{P}<0,05)$. 


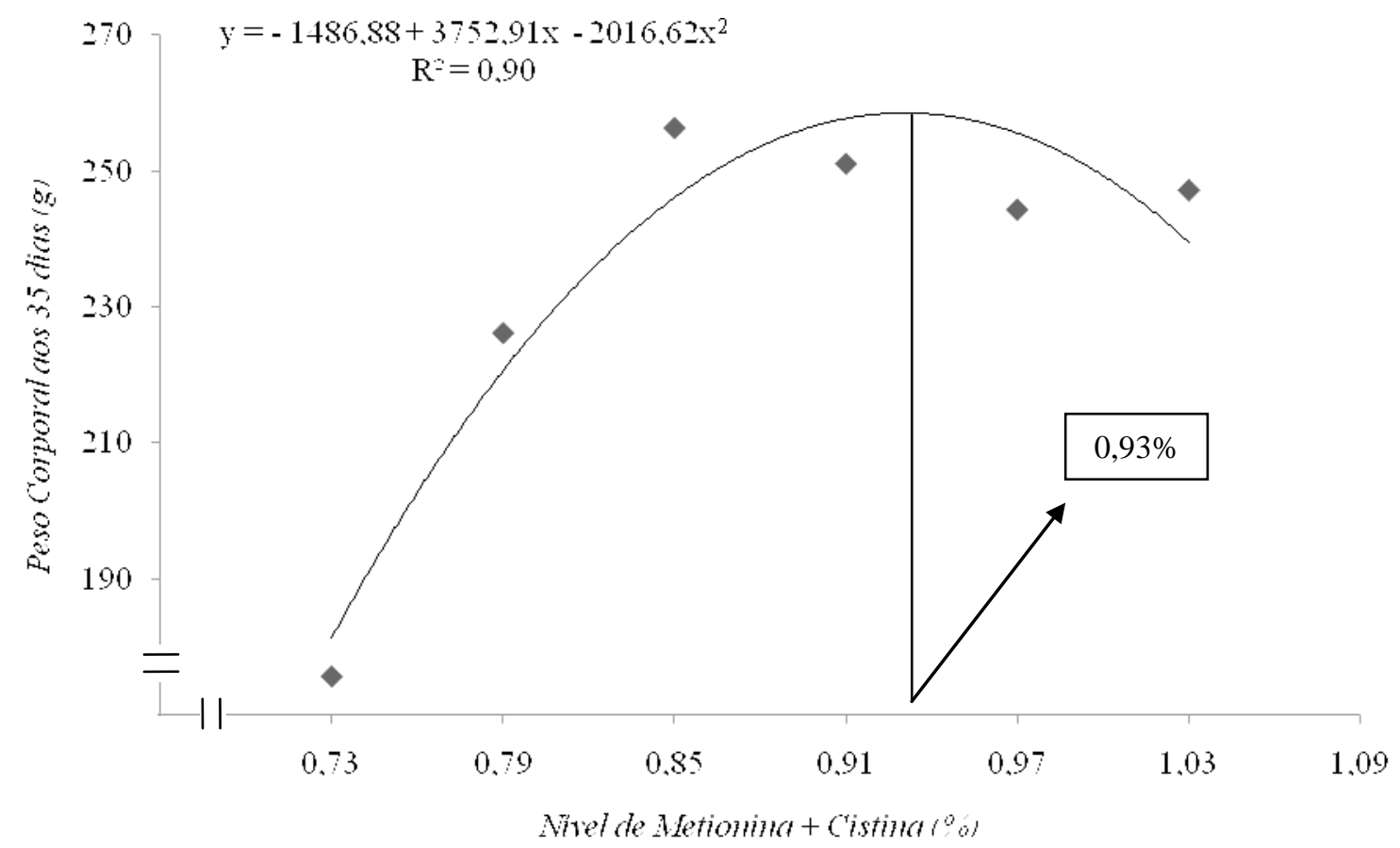

Figura 1. Regressão do peso corporal no $35^{\circ}$ dia de idade de codornas de corte EV1 em relação ao nível de metionina+cistina da dieta.

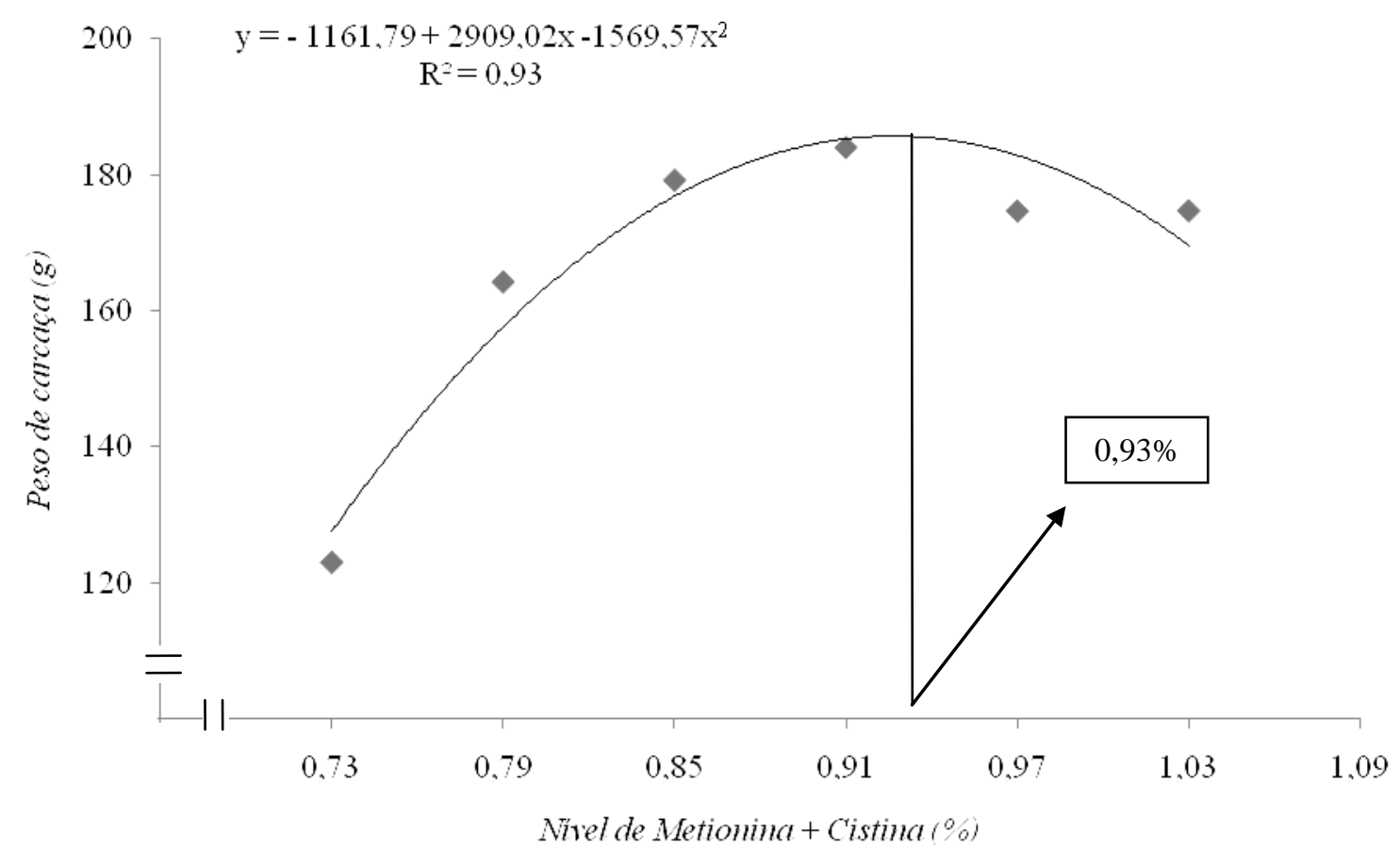

Figura 2. Regressão do peso de carcaça de codornas de corte EV1 em relação ao nível de metionina+cistina da dieta. 


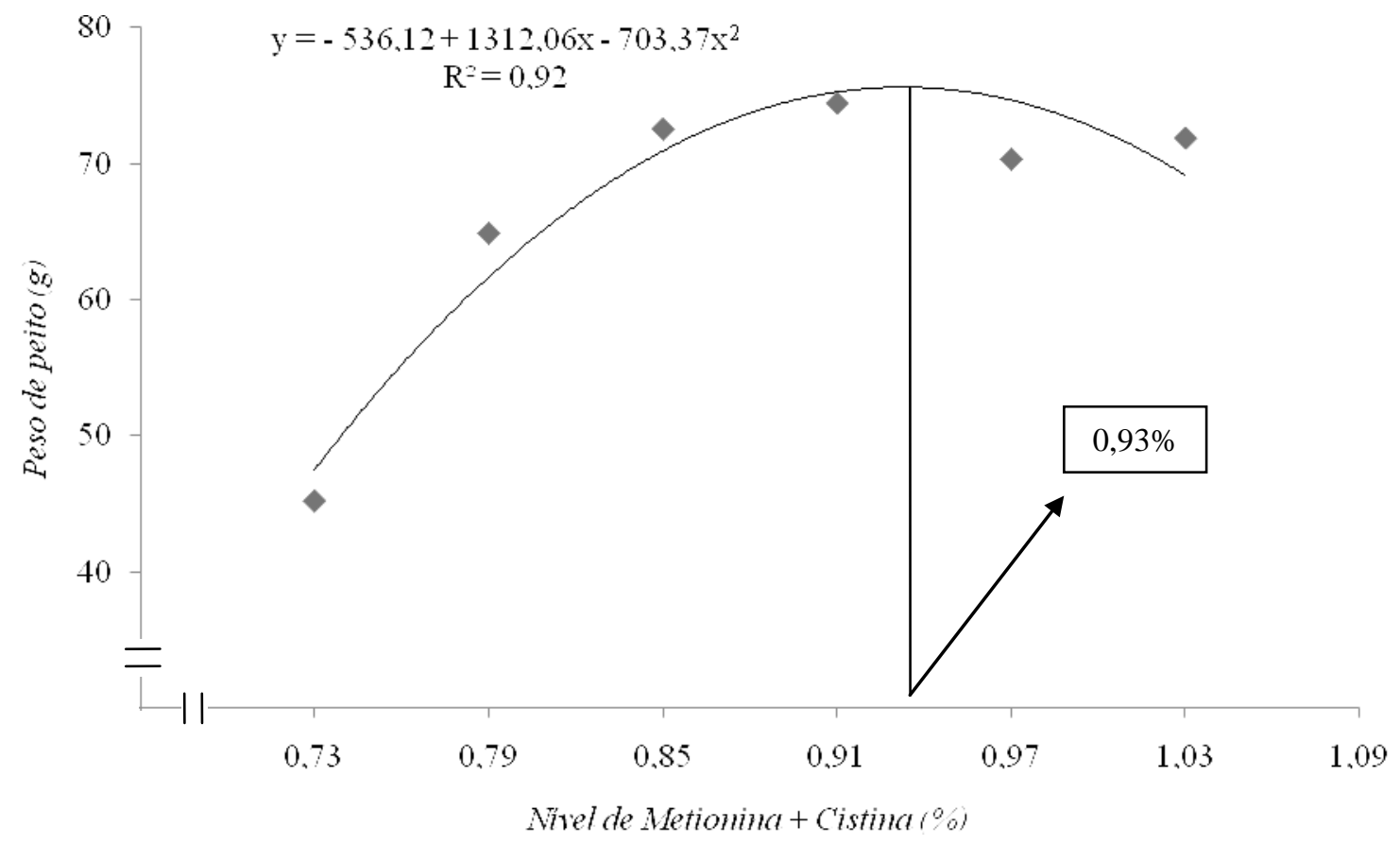

Figura 3. Regressão do peso de peito de codornas de corte EV1 em relação ao nível de metionina+cistina da dieta.

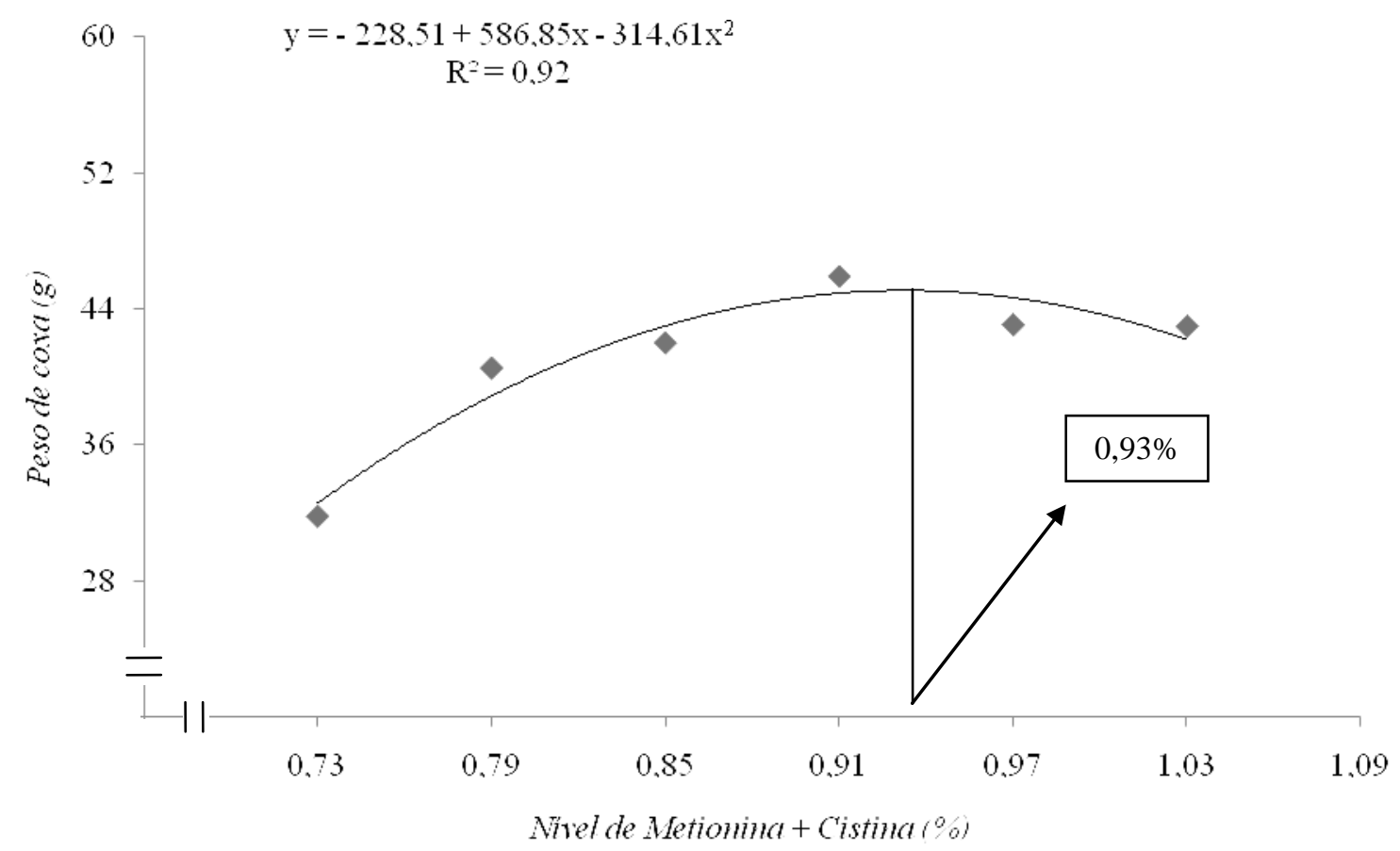

Figura 4. Regressão do peso de coxa de codornas de corte EV1 em relação ao nível de metionina+cistina da dieta. 


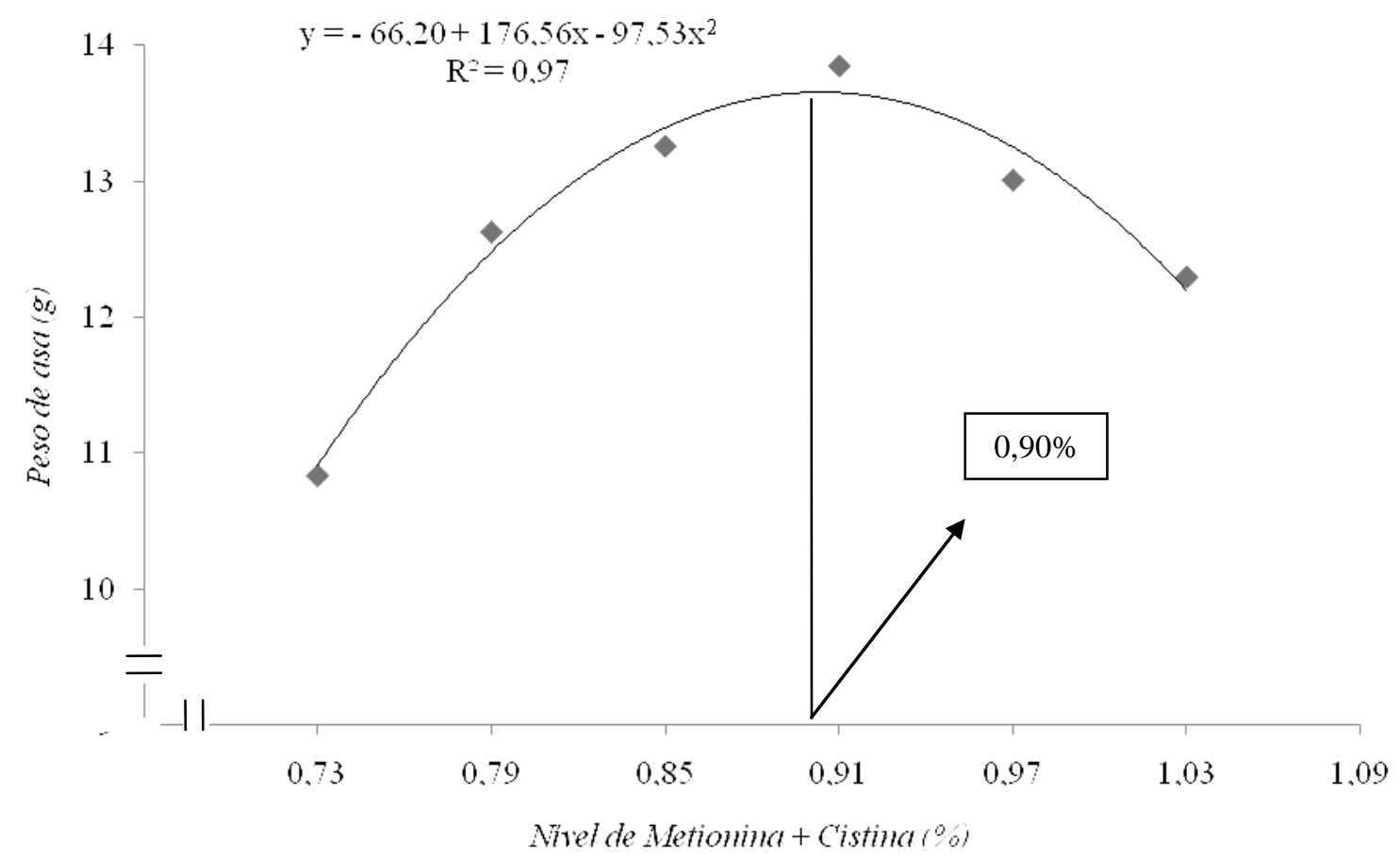

Figura 5. Regressão do peso de asa de codornas de corte EV1 em relação ao nível de metionina+cistina da dieta.

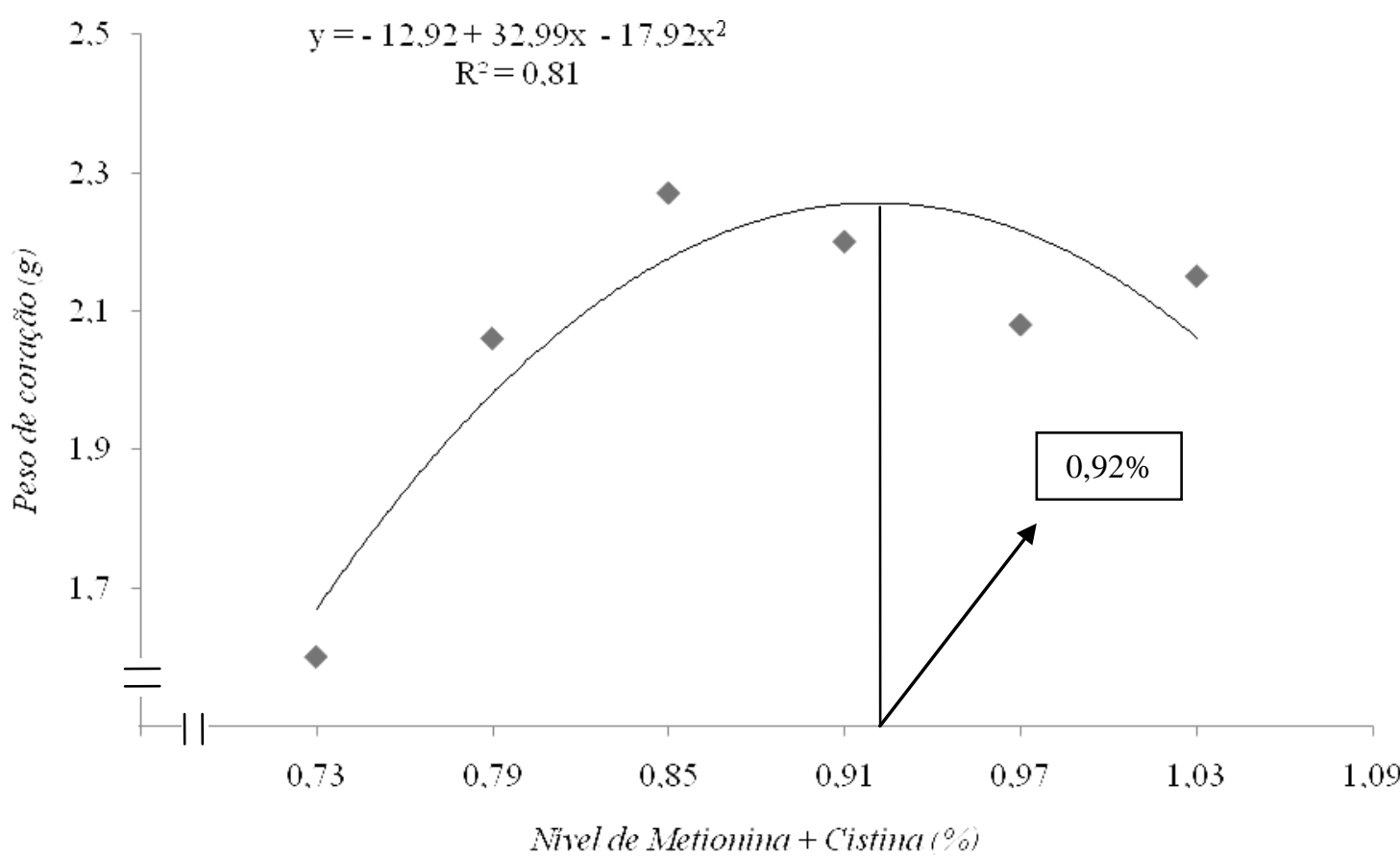

Figura 6. Regressão do peso de coração de codornas de corte EV1 em relação ao nível de metionina+cistina da dieta. 
O fígado é órgão responsável pela síntese lipídica nas aves, e normalmente a porcentagem média de lipídeos hepáticos na segunda e quarta semanas de idade é similar em ambos os sexos. No entanto, após iniciado o ciclo reprodutivo das codornas, o conteúdo hepático das fêmeas $\left(35^{\circ}\right.$ dia de idade) é maior do que o dos machos; em decorrência disso, observou-se maior peso do fígado das fêmeas.

Observam-se, à semelhança dos relatos realizados por Silva et al. (2012), redução na taxa de crescimento, diminuição da massa muscular e aumento na retenção de nutrientes no ovário-oviduto, com incremento na deposição de gordura abdominal e nas vísceras, durante a fase final de crescimento das codornas.

As fêmeas também apresentaram maior peso de gordura abdominal (Tab. 2) do que os machos, o que não é desejável, mas é resultado da existência de adipócitos de maior tamanho nas fêmeas e do metabolismo mais acelerado dos machos (Langslow e Lewis, 1974).

Houve efeito quadrático $(\mathrm{P}<0,05)$ dos níveis de metionina+cistina sobre o rendimento de peito (Tab. 3), com rendimento máximo de peito estimado para codornas alimentadas com dietas contendo $0,96 \%$, sugerindo que a exigência de metionina+cistina total para máximo rendimento de peito é maior do que a do peso corporal (Tab. 2).

Houve efeito linear decrescente do nível de metionina+cistina sobre o rendimento de moela (Tab. 3), assim maiores rendimentos foram observados em codornas alimentadas com o menor nível de metionina+cistina testada neste estudo (0,73\%).

Resultados similares aos do presente estudo para rendimento de peito foram observados em outras espécies de aves. Amarante Jr. et al. (2005), por exemplo, ao avaliarem a influência de níveis de metionina+cistina $(0,66 ; 0,70 ; 0,74 ; 0,78 ; 0,82$ e $0,86 \%$ ) em dietas para frangos do $22^{0}$ ao $42^{0}$ dia de idade, também observaram efeito quadrático do nível de metionina+cistina sobre o rendimento de peito, com máximo estimado para aves alimentadas com dietas contendo $0,82 \%$.
Resultados contraditórios aos observados nesta pesquisa foram obtidos em codornas de corte por Corrêa et al. (2010), que testaram os mesmos níveis de metionina+cistina do presente estudo $(0,73$ a $1,03 \%)$ e não observaram efeito significativo do nível nutricional da dieta sobre o peso e o rendimento de carcaça, peito, coxa, gordura abdominal, fígado, moela e coração. Deve ser salientado, no entanto, que as codornas que participaram da pesquisa realizada pelos referidos autores passaram a ser alimentadas com as dietas experimentais, por limitação nas instalações de pesquisa à época, somente a partir do sétimo dia de idade, mas foram alimentadas com dieta única no período inicial do experimento (do nascimento aos sete dias de idade), o que pode ter comprometido seu crescimento subsequente.

Da mesma forma, em frangos de corte, Whitaker et al. (2002) não verificaram influência significativa dos níveis de metionina testados sobre os pesos e os rendimentos de carcaça, coxas, asas, dorso e gordura abdominal.

Os rendimentos de carcaça, de asa e de fígado foram influenciados pelo sexo das codornas independentemente dos níveis nutricionais administrados (Tab. 3).

Os machos apresentaram maiores rendimentos de carcaça e asa do que as fêmeas (Tab. 3). Esse maior rendimento de carcaça dos machos pode ser explicado pelo menor peso de gordura abdominal e também menor peso do fígado dos machos (Tab. 2) e maior peso de órgãos reprodutivos das fêmeas, o que favorece o maior rendimento de carcaça dos machos. Ao estudarem efeito de diferentes níveis de proteína bruta na dieta (20; 22; 24 e 26\%), Oliveira et al. (2005) também verificaram maiores rendimentos de carcaças nos machos no $49^{0}$ dia de idade.

Silva et al. (2007), ao avaliarem o efeito de nove planos nutricionais sobre $\mathrm{o}$ rendimento de carcaças de codornas de corte, verificaram que, apesar de as fêmeas apresentarem maiores pesos corporais, os machos apresentam maior rendimento de carcaça em decorrência dos maiores pesos de ovário e oviduto apresentados pelas fêmeas e dos maiores pesos do fígado e da gordura abdominal apresentados pelos machos. Corrêa et al. (2010) também encontraram maior rendimento de carcaça nos machos. 
Tabela 3. Rendimento de carcaça (\%), rendimento de cortes (\%), rendimento de vísceras comestíveis (\%) e rendimento de gordura abdominal (\%), em relação aos níveis de metionina+cistina da dieta

\begin{tabular}{|c|c|c|c|c|c|c|c|c|}
\hline \multirow{2}{*}{ Variáveis } & \multirow{2}{*}{ Sexo } & \multicolumn{6}{|c|}{ Níveis de metionina+cistina total (\%) } & \multirow{2}{*}{ Média } \\
\hline & & 0,73 & 0,79 & 0,85 & 0,91 & 0,97 & 1,03 & \\
\hline \multirow{2}{*}{$\begin{array}{l}\text { Rend. de } \\
\text { carcaça (\%) }\end{array}$} & $\mathbf{M}$ & 69,25 & 73,20 & 72,16 & 74,79 & 73,38 & 74,35 & $72,85 \mathrm{~A}$ \\
\hline & $\mathbf{F}$ & 70,58 & 72,10 & 68,77 & 71,78 & 69,92 & 68,22 & $70,23 B$ \\
\hline \multirow{2}{*}{ Rend. de peito (\%) } & $\mathbf{M}$ & 36,28 & 39,68 & 40,62 & 41,34 & 40,04 & 40,63 & $39,76 \mathrm{~A}$ \\
\hline & $\mathbf{F}$ & 36,88 & 39,31 & 40,30 & 39,44 & 40,60 & 41,44 & $39,66 \mathrm{~A}$ \\
\hline \multirow{2}{*}{ Rend. de coxa (\%) } & $\mathbf{M}$ & 26,16 & 24,66 & 24,05 & 24,99 & 24,61 & 24,36 & $24,81 \mathrm{~A}$ \\
\hline & $\mathbf{F}$ & 25,61 & 24,72 & 22,90 & 24,90 & 24,67 & 24,82 & $24,60 \mathrm{~A}$ \\
\hline \multirow[t]{2}{*}{ Rend. de asa (\%) } & $\mathbf{M}$ & 9,33 & 7,83 & 7,76 & 7,62 & 7,76 & 6,98 & $7,88 \mathrm{~A}$ \\
\hline & $\mathbf{F}$ & 8,49 & 7,60 & 7,04 & 7,45 & 7,17 & 7,09 & $7,47 \mathrm{~B}$ \\
\hline \multirow{2}{*}{ Rend. de fígado (\%) } & $\mathbf{M}$ & 3,32 & 2,62 & 2,33 & 2,36 & 2,36 & 2,57 & $2,59 B$ \\
\hline & $\mathbf{F}$ & 3,66 & 3,67 & 3,89 & 3,83 & 5,20 & 4,17 & $4,07 \mathrm{~A}$ \\
\hline \multirow{2}{*}{ Rend. de moela (\%) } & $\mathbf{M}$ & 3,38 & 2,79 & 2,42 & 2,60 & 2,46 & 2,27 & $2,65 \mathrm{~A}$ \\
\hline & $\mathbf{F}$ & 3,16 & 2,81 & 2,62 & 2,60 & 2,58 & 2,46 & $2,71 \mathrm{~A}$ \\
\hline \multirow{2}{*}{$\begin{array}{l}\text { Rend. De } \\
\text { coração (\%) }\end{array}$} & $\mathbf{M}$ & 1,37 & 1,35 & 1,23 & 1,24 & 1,22 & 1,27 & $1,28 \mathrm{~A}$ \\
\hline & $\mathbf{F}$ & 1,20 & 1,18 & 1,30 & 1,14 & 1,16 & 1,19 & $1,20 \mathrm{~A}$ \\
\hline \multirow{3}{*}{$\begin{array}{l}\text { Rend. de gord. } \\
\text { abdominal (\%) }\end{array}$} & $\mathbf{M}$ & 0,69 & 0,55 & 0,73 & 0,99 & 0,58 & 1,37 & $0,82 \mathrm{~A}$ \\
\hline & $\mathbf{F}$ & 0,98 & 1,10 & 1,30 & 1,15 & 0,86 & 0,94 & $1,06 \mathrm{~A}$ \\
\hline & \multicolumn{6}{|c|}{$\begin{array}{c}\text { Equações de regressão significativas para níveis de } \\
\text { metionina+cistina }\end{array}$} & \multicolumn{2}{|c|}{$\begin{array}{c}\text { Ponto de melhor } \\
\text { desempenho }\end{array}$} \\
\hline Rend. de peito & \multicolumn{4}{|c|}{$\hat{Y}_{i}=-24,64+136,66_{X_{i}}-71,20 X_{i}^{2}$} & \multicolumn{2}{|c|}{$\left(\mathrm{R}^{2}=0,87\right)$} & \multicolumn{2}{|c|}{0,96} \\
\hline Rend. de moela & \multicolumn{3}{|c|}{$\hat{Y}_{i}=4,85-2,47 X_{i}$} & & \multicolumn{2}{|c|}{$\left(\mathrm{R}^{2}=0,76\right)$} & \multicolumn{2}{|c|}{0,73} \\
\hline
\end{tabular}

Médias seguidas por letras distintas na coluna, entre os sexos, dentro de cada variável diferem entre si pelo teste de Fisher $(\mathrm{P}<0,05)$.

A síntese lipídica no organismo é realizada pelo fígado. Os lipídeos sintetizados são exportados para o ovário das fêmeas, a fim de garantir o crescimento das gemas durante a fase reprodutiva das codornas (Corrêa et al., 2008). Assim, maior rendimento do fígado apresentado pelas fêmeas (Tab. 3) pode estar relacionado à maturação sexual dessas aves. Nessa ocasião, o peso do fígado das fêmeas é $80 \%$ maior do que o dos machos, e o peso da carcaça apenas $12,5 \%$, (Tab. 1), o que resulta em maior rendimento do fígado (Tab. 2), uma vez que o rendimento do fígado representa a razão entre essas duas variáveis, expressa em porcentagem. De modo similar, Silva et al. (2007) também constataram maior rendimento de fígado nas fêmeas em relação aos machos.

\section{CONCLUSÕES}

A exigência de metionina+cistina para maiores pesos de carcaça e peito é 0,93\% e do rendimento de peito $0,96 \%$, para ambos os sexos de codornas de corte EV1, o que corresponde às relações de metionina+cistina: lisina de 0,71 e 0,74 , respectivamente.

\section{AGRADECIMENTOS}

À FAPEMIG, Capes e CNPq pelos recursos disponibilizados durante execução do projeto, e à AJINOMOTO pela doação dos aminoácidos.

\section{REFERENCIAS}

AMARANTE JR, V.S.; COSTA, F.G.P.; BARROS, L.R. et al. Níveis de metionina + cistina para frangos de corte nos períodos de 22 a 42 e de 43 a 49 dias de idade. Rev. Bras. Zootec., v.34, p.1195-1201, 2005.

CORRÊA, G.S.S.; SILVA, M.A.; CORRÊA, A.B. et al. Exigência de metionina + cistina total para codornas de corte em crescimento. Arq. Bras. Med. Vet. Zootec., v.58, p.414-420, 2006.

CORRÊA, G.S.S.; SILVA, M.A.; CORRÊA, A.B. et al. Exigências em proteína bruta para codornas de corte EV1 em crescimento. Arq. Bras. Med. Vet. Zootec., v.59, p.1278-1286, 2007. 
CORRÊA, G.S.S.; SILVA, M.A.; CORRÊA, A.B. et al. Nível de proteína bruta para codornas de corte durante o período de crescimento. Arq. Bras. Med. Vet. Zootec., v.60, p.209-217, 2008.

CORRÊA, G.S.S.; SILVA, M.A.; CORRÊA, A.B. et al. Níveis de metionina + cistina para características de desempenho e de carcaça em codornas de corte EV2. Arq. Bras. Med. Vet. Zootec., v.62, p.940-947, 2010.

CORRÊA, G.S.S.; SILVA, M.A.; FONTES, D.O. et al. Efeito de diferentes níveis de proteína e energia sobre o rendimento de carcaça de codornas européias. Arq. Bras. Med. Vet. Zootec., v.57, p.266-271, 2005.

GARCIA, E.A. Codornas para a produção de carne. In: SIMPÓSIO INTERNACIONAL DE COTURNICULTURA, 01., 2002, Lavras, Anais... Lavras: UFLA, 2002. p.97-108.

LANGSLOW, D.R.; LEWIS, R.J. Alterations with age in composition and lipolytic activity of adipose tissue from male and female chickens. Br. Poult. Sci., v.15, p.267-273, 1974.

MURAKAMI, A.E.; ARIKI, J. (Ed). Produção de codornas japonesas. Jaboticabal: Funep, 1998. 79p.

NUTRIENT requeriments of poultry. National Reserch Council. 9. ed. Washington: National Academy of Sciences, 1994. 155p.

OLIVEIRA, E.G.; ALMEIDA, M.I.M.; MENDES, A.A. et al. Avaliação do rendimento de carcaça de codornas para corte alimentadas com dietas com diferentes níveis protéicos. Arch. Vet. Sci., v.10, p.42-45, 2005.
PINTO, R.; FERREIRA, A.S.; DONZELE, J.L. et al. Exigência de metionina mais cistina para codornas japonesas em crescimento. Rev. Bras. Zootec., v.32, p.1174-1181, 2003.

ROSTAGNO, H.S.; ALBINO, L.F.T.; DONZELE, J.L. et al. (Ed). Tabelas Brasileiras para Aves e Suínos. Composição de Alimentos e Exigências Nutricionais. Viçosa: UFV, 2005. 183p.

SCHUTTE, J.B.; PACK, M. Effects of dietary sulphur containing amino acids on performance and breast meat deposition of broilers chicks during the growing, and finishing phases. $\mathrm{Br}$. Poult. Sci., v.36, p.747-762, 1995.

SILVA, E.L.; SILVA, J.H.V.; FILHO, J.J. et al. Efeito do plano de nutrição sobre o rendimento de carcaça de codornas tipo carne. Ciênc. Agrotec., v.31, p.514-522, 2007.

SILVA, E.L.; SILVA, J.H.V.; JORDÃO FILHO, J. et al. Redução dos níveis de proteína e suplementação aminoacídica em rações para codornas europeias (Coturnix coturnix coturnix). Rev. Bras. Zootec., v.35, p.822-829, 2006.

SILVA, J.H.V.; JORDÃO FILHO, J.; COSTA, F.G.P. et al. Exigências nutricionais de codornas. Rev. Bras. Saúde Prod. Anim., v.13, p.775-790, 2012.

SISTEMA para análise estatística e genéticaSAEG. Universidade Federal de Viçosa. Viçosa, MG: Fundação Arthur Bernardes, 2009.

WHITAKER, H.M.A.; MENDES, A.A.; GARCIA, E.A. et al. Efeito da suplementação de metionina sobre o desempenho e a avaliação de carcaças de frangos de corte. Bras. J. Poult. Sci., v.4, p.001-009, 2002. 